\title{
APLIKASI GAME EDUKASI PUZZLE DENGAN KECERDASAN BUATAN BERBASIS ANDROID
}

\author{
Tamra $^{1}, \operatorname{Rahman}^{2}$, Markani $^{3}$, Irnawati $^{4}$ \\ ${ }^{1,3}$ Sistem Informasi, STMIK AKBA, Makassar, Indonesia \\ ${ }^{2,4}$ Sistem Informasi, STMIK AKBA, Makassar, Indonesia \\ 1'tamra@akba.ac.id, ${ }^{2}$ abdrahman@akba.ac.id, ${ }^{3}$ markani@akba.ac.id, ${ }^{4}$ irnainns@gmail.com
}

\begin{abstract}
ABSTRAK
Penelitian ini bertujuan untuk mengetahui perancang dan implementasi aplikasi game edukasi puzzle dengan kecerdasan buatan menggunakan finite state machine (FSM) dan shuffle random berbasis android berbasis android. Metode pengumpulan data dengan cara browsing internet, mempelajari buku, jurnal, skripsi, dan sistem analisis SWOT. Algoritma shuffle random untuk pengacakan puzzle dan agent game menggunakan sistem kontrol (finite state machine) FSM sebagai AI (artificial intelligence). Metode UML (unified modeling language). Hasil penelitian ini aplikasi game pengenalan nama buah, hewan, dan transportasI berupa .APK dan jalankan pada smartphone android, game edukasi "game puzzle" berbasis android dapat mainkan untuk anak-anak usia dini dengan hasil pengujian angket dari 5 pertanyaan dengan 12 responden terbukti sangat layak dengan indeks persentase $96 \%$.
\end{abstract}

Kata Kunci: Game Edukasi, Puzzle, Android, Finite State Mechine

\begin{abstract}
This study aims to see the designer and implementation of a puzzle educational game application with artificial intelligence using a finite state machine (FSM) and android-based random shuffle based on android. The data research method is by browsing the internet, studyng books, journals, theses, and SWOT system analysis. The shuffle random algorithm for randomizing puzzles and game agents uses a control system (finite state machine) FSM as AI (artificial intelligence). UML method (integrated modeling language). The results of this research application of fruit, animal, and transportation name recognition games in the form of .APK and run on an android smartphone, educational games "puzzle games" based on android can be played for early childhood with the results of testing a questionnaire of 5 questions with 12 respondents proved to be very feasible with a percentage index of $96 \%$.
\end{abstract}

Keywords: Educational Games, Puzzles, Android, Finite State Machine. 
Jurnal Ilmiah Ilmu Komputer Vol. 5, No. 1, April 2019

Fakultas Ilmu Komputer

Universitas AL Asyariah Mandar

\section{PENDAHULUAN}

\subsection{Latar Belakang}

Metode edukasi konvensional pada pengenalan nama buah, hewan, dan transportasi menggunakan media dari buku. Di mana buku mudah rusak. Memerlukan buku dalam jumlah yang banyak, memerlukan tempat menyimpan buku.

Gambar yang tidak berwarna, tidak bergerak, tidak bersuara, dan membutuhkan penjelasan, baik dari guru atau orang tua, sehingga anak-anak membutuhkan waktu lebih lama untuk mengerti, karena menggunakan sistem hafalan. Pada anak-anak usia dini keinginan bermain lebih besar dibandingkan minat belajar sehingga mudah bosan. Pertumbuhan trend teknologi untuk media pembelajaran dan permainan saat ini cenderung pada mobile games [1]

Berdasarkan penelitian sebelumnya terkait game edukasi puzzle yang diteliti oleh [2] dalam penelitiannya menggunakan perangkat visual basic 6 dan algoritma $A^{*}$ menggunakan fungsi heuristic. Penelitian juga dilakukan oleh [2] meneliti tentang pengenalan nama hewan dalam bahasa Inggris berbasis adobe flash CS6, menggunakan multimedia berbasis komputer dalam program adobe flash CS6.

Pada penelitian sebelumnya yang telah dilakukan oleh [2] dalam penelitiannya menggunakan perangkat visual basic 6 dan algoritma $A^{*}$ yang menerapkan fungsi heuristic untuk menyusun angka menjadi susunan angka yang benar.

[3] Menggunakan multimedia berbasis komputer dan aplikasi adobe flash CS6 dapat menambah minat bejalar anak usia dini mengenal nama hewan dalam bahasa Inggris. Kelemahan dari masing-masing penelitian sebelumnya yaitu perlu tingkat kesulitan (level) dan metode dalam pengacakan potongan puzzle dimana pengguna (user) mudah dalam menebaknya sehingga mudah jenuh dan bosan..

Pada metode sebelumnya ada beberapa kelemahan, salah satunya adalah perlu metode pengacakan potongan puzzle membuat user mudah jenuh dan bosan. Oleh karena itu peneliti membuat game eduaksi berupa aplikasi untuk memudahkan dalam pembelajara berupa pengenal nama buah, hewan, dan transportasi dengan game puzzle gambar 3D berbasis android. Penelitan ini menggunakan metode Finite State Machine (FSM) yang merupkan sebuah metodologi perancangan system control yang menggambarkan tingkah laku atau prinsip kerja system [4]
(P) ISSN 2442-451X

Pada aplikasi mengunakan metode algoritma shuffle random membantu pengacakan potongan gambar dan agent game menerapkan finite state machine (FSM). Pada agent game menarapkan metode finite state machine (FSM) membantu dalam mengontrol aksi, reaksi, mengamati, dan bertindak pada suatu kondisi. Agent game berfugsi sebagai pemberitahuan atau notifikasi kepada pemain untuk membantu penyusunan potongan puzzle.

Berdasarkan hal tersebut penelitian ini menerapkan aplikasi game edukasi puzzle dengan kecerdasan buatan berbasis android dalam pengenalan nama buah, hewan, dan transportasi. Dengan menggunakan algoritma shuffle random untuk pengacakan puzzle dan agent game menggunakan sistem kontrol finite state machine (FSM) sebagai AI.

\section{TINJAUAN PUSTAKA}

\subsection{Game Edukasi}

Game edukasi terdiri dari dua kata yaitu "game" dan "edukasi" dalam kamus bahasa Indonesia "game" diartikan sebagai permainan. Edukasi dalam kamus bahasa Inggris education berarti pendidikan sedangkan dalam kamus bahasa Indonesisa pendidikan diartikan sebagai proses pengubahan sikap dan tingkah laku seseorang atau sekelompok orang dalam mendewasakan manusia melalui upaya pengajaran dan pelatihan. Pendidikan berasal dari kata didik atau mendidik yang berarti memelihara dan membentuk latihan [5].

\subsection{Puzzle}

Kata Puzzle berasal dari bahasa Inggris yang berarti teka-teki atau bongkar pasang, media puzzle suatu media sederhana yang dimainkan dengan bongkar pasang. Puzzle merupakan suatu masalah dimana orang yang mencoba memecahkannya berpikir. [6] Puzzle digunakan untuk menghibur dan membantu kemampuan logika dalam mengenali pola-pola untuk mengatasinya. Puzzle adalah suatu game atau permainan merangkai bagian-bagian terpisah dari gambar utuh yang berfungsi menguji pengetahuan seseorang. Dalam penelitian menggunakan jenis puzzle jigsaw adalah teka-teki yang dibuat dari sebuah gambar yang dipotong-potong dengan desain khusus dan dapat disambung kembali membentuk gambar yang utuh.

\subsection{Finite State Macine}

Finite state machine (FSM) didefinisikan sebagai perangkat komputasi yang memiliki input berupa string dan output yang merupakan satu dari dua nilai yang dapat di-accept and reject [7]. Finite automata merupakan salah satu model matematika dengan sistem masukan dan keluaran diskrit. Sistem dapat berada disalah satu dari sejumlah sehingga konfigurasi internal disebut state. 
FSM adalah sebuah metodologi perancangan sistem kontrol yang menggambarkan tingkah laku atau prinsip kerja sistem dengan menggunakan tiga yaitu state (keadaan), event (kejadian), dan action (aksi). Sistem dapat beralih atau bertransisi menuju (state) lain jika mendapatkan masukan atau event tertentu, baik yang berasal dari perangkat luar atau komponen dalam sistemnya itu sendiri. Transisi keadaan umumnya disertai berupa aksi yang dilakukan sistem ketika menanggapi input-an yang terjadi. Aksi yang dilakukan tersebut dapat berupa aksi yang sederhana atau melibatkan rangkaian proses yang relatif kompleks.

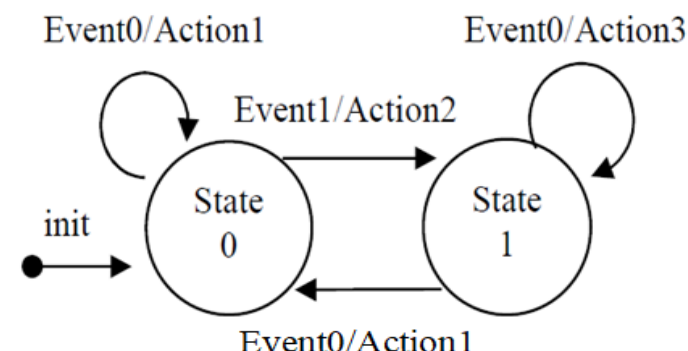

Gambar 1. Diagram State Sederhana

Pada gambar 1 memperlihatkan diagram FSM dengan dua state dan dua buah input serta empat buah aksi output yang berdeda. Ketika sistem mulai dihidupkan, sistem akan bertransisi menuju state 0, pada keadaan disistem akan menghasilkan action 1 jika terjadi masukan event 0 , sedangkan jika terjadi event 1 maka action 2 akan dieksekusi kemudian sistem selanjutnya bertransisi ke keadaan state 1 dan seterusnya.

FSM terdiri dari dua jenis FSM yaitu ber-output dan tidak ber-output. FSM yang tidak ber-output digunakan untuk mengenalkan bahasa dalam komputer, dengan input yang dimasukkan akan diperoleh apakah input tersebut dikenali oleh bahasa komputer atau tidak. Penggunaan FSM yang tidak ber-output disebut progam compiler dimana pada program akan memeriksa apakah perintah yang digunakan oleh pengguna benar atau salah. Sedangkan FSM beroutput digunakan untuk merancang mesin atau sistem. Dalam penelitian ini FSM yang akan digunakan FSM beroutput.

\subsection{Android}

Android merupakan suatu sistem operasi yang dirancang khusus untuk smartphone dan tablet. Sistem android memiliki basis linux yang dijadikan sebagai pondasi atau dasar dari sistem operasi android. Linux sendiri merupakan sistem operasi yang dirancang khusus untuk computer. Android yang dirancang khusus untuk dipasang pada perangkat-perangkat yaitu mobile touchscreen seperti smartphone dan tablet. Sehingga sistem operasi yang berada di dalam smartphone saat ini yang menyesuaikan dari spesifikasi kelas low-end hingga high-end. Sehingga perkembangan sistem android yang cukup meningkat tajam.

Android merupakan sistem operasi yang terbuka (open source) yang mana berarti jika pihak Google memperbolehkan dan membebaskan bagi pihak manapun untuk dapat mengembangkan sistem operasi tersebut. Bahkan pengguna sendiri pun juga dapat mengembangkan sistem android yang memang sesuai dengan keinginan pengguna.

Android menggunakan nama-nama makanan untuk membedakan versi sistem android yang diluncurkannya. Android menggunakan huruf depan dari nama makanan tersebut sebagai penanda peningkatan versi sistemnya. Mulai dari cupcake android $1.5(\mathrm{C})$, donuts android 1.6 (D), eclair android 2.0-2.1 (E) atau marshmallow android 6.0 (M). Berbagai perangkat android telah diuji kualitas performa dalam menjalankan game [8]

\section{METODE PENELITIAN}

\subsection{Metode Pengumpulan Data}

Penelitian ini menggunakan metode studi pustaka dengan melakukan browsing internet dan melakukan pembelajaran terhadap jurnal dan skripsi yang relevan sesuai dengan topik penelitian yang dijadikan sebagai bahan acuan dalam penelitian. Data yang dapat digunakan dalam penyusunan landasan teori, metodologi penelitian.

\subsection{Metode Analisis}

Pada penelitian ini menggunakan analisis SWOT (Strength, Weakness, opportunities, threats).

\subsection{Metode Perancangan Sistem}

Perancangan aplikasi game puzzle menggunakan perancangan UML (unified modeling language) yang terdiri atas beberapa diagram yaitu use case, sequence, activity, class, dan statechart diagram [9].

\section{1). Use Case Diagram}

Use case diagram menggambarkan apa saja yang dapat di akses oleh pengguna aplikasi (aktor). Pada perancangan use case diagram yang mengambarkan interaksi antara satu atau lebih actor dengan sistem yang dibuat yaitu pada aplikasi puzzle, dapat dilihat pada gambar 2 . 
Jurnal Ilmiah Ilmu Komputer Vol. 5, No. 1, April 2019

Fakultas Ilmu Komputer

Universitas AL Asyariah Mandar

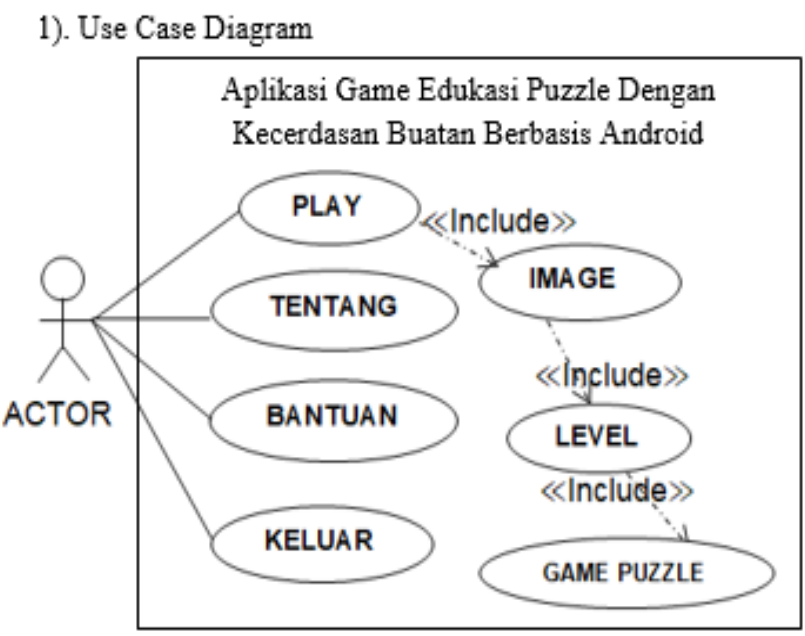

Gambar 2. Use Case Diagram

\section{2). Activy Diagram}

Activity diagram merupakan diagram yang menggambarkan aliran kerja (worlflow) atau aktivitas dari sebuah sistem atau proses bisnis. Pada perancangan activity diagram yang menggambarkan aliran kerja atau aktivitas dari sistem yang dibuat. Pada gambar 3 menjelaskan tentang aliran aktivitas yang terjadi pada aplikasi puzzle

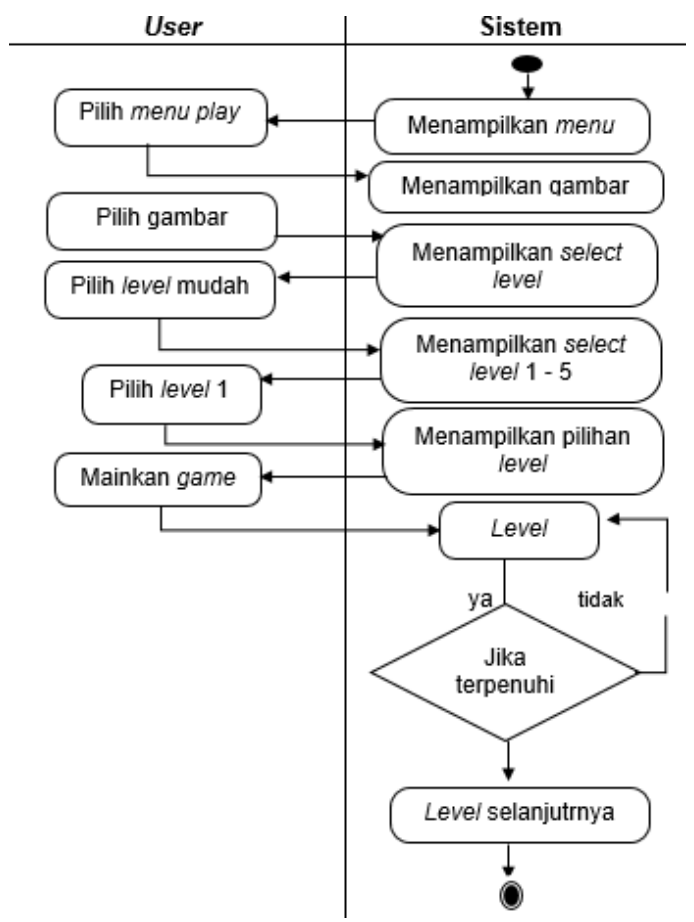

Gambar 3. Activy Diagram

\section{3). Sequence Diagram}

Pada perancangan sequence diagram merupakan gambaran objek pada use case yang akan mendeskripsikan waktu hidup objek dan message yang kemudia dikirimkan dan diterima antara objek seperti pada gambar 4 .

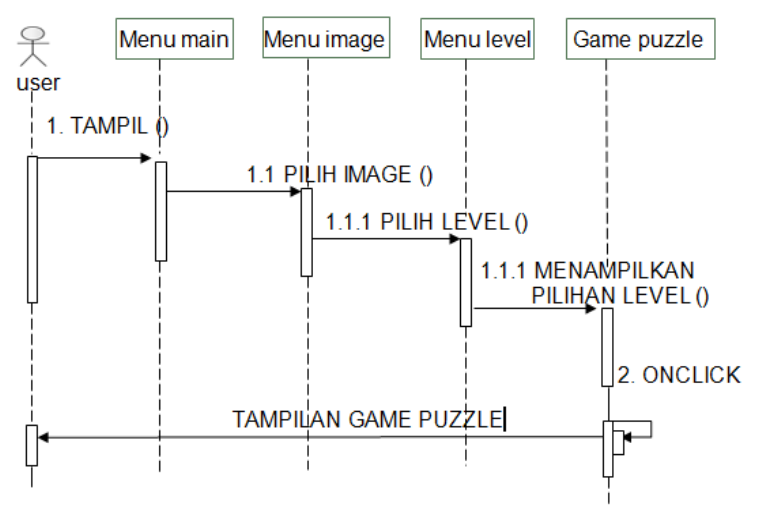

Gambar 4. Sequence Diagram

\section{4). Class Diagram}

Class diagram adalah diagram yang menggambarkan struktur sistem dari segi pendefinisian kelas-kelas yang akan dibuat untuk membuat sistem seperti pada gambar 3.4 berikut

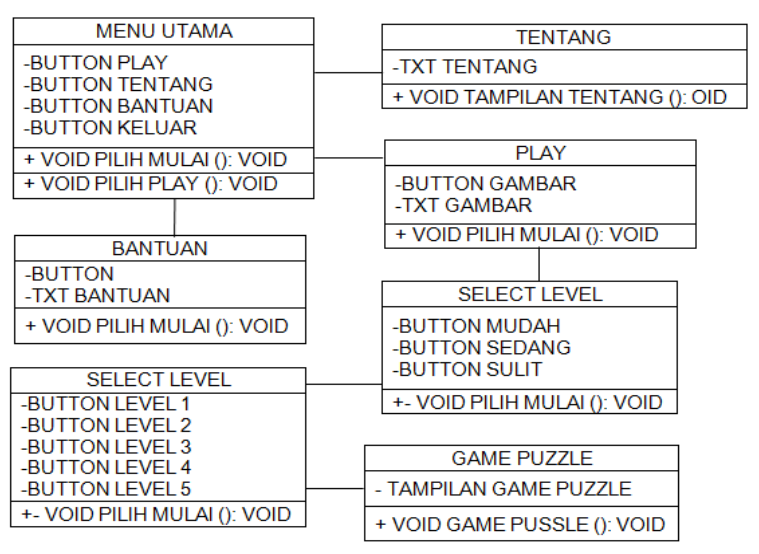

Gambar 5. Class Diagram

\section{5). Statechart Diagram}

Statechart diagram adalah sebuah diagram yang menggambar, memperlihatkan serta mendeskripsi tentang perilaku system [10].Pada statechart diagram dalam game eduaksi puzzle seperti pada gambar 5 . 
Jurnal Ilmiah Ilmu Komputer Vol. 5, No. 1, April 2019

Fakultas Ilmu Komputer

Universitas AL Asyariah Mandar

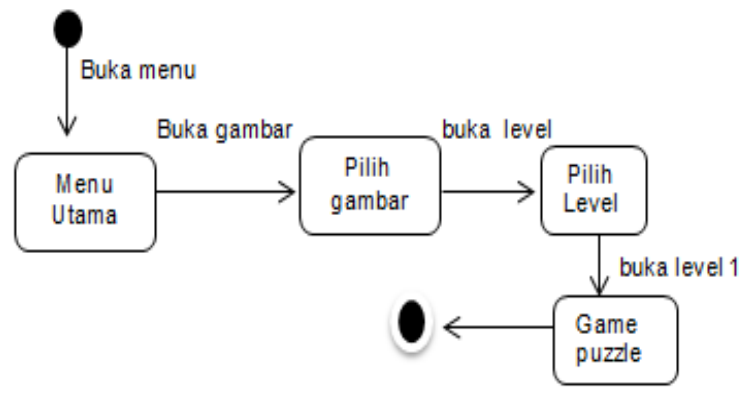

Gambar 5. Statechart Diagram

\section{HASIL PENELITIAN}

\subsection{Hasil}

Hasil pada penelitian ini dilakukan dengan menampilkan sistem yang dibuat. Hasil ini berisi pengujian black box dan pengujian skala likert.

Pengujian black box dilakukan dengan memastikan fungsi dari setiap perintah di dalam aplikasi dapat berjalan lancar dan kemudian diberikan kepada user untuk melakukan testing terhadap aplikasi.

Tabel 1 Pengujian black box

\begin{tabular}{|c|c|c|c|}
\hline No & Item uji & Output & Keterangan \\
\hline 1 & $\begin{array}{l}\text { Memilih } \\
\text { menu play }\end{array}$ & $\begin{array}{l}\text { Menampilkan slide } \\
\text { beberapa gambar } \\
\text { buah, hewan, dan } \\
\text { transportasi }\end{array}$ & Berhasil \\
\hline 2 & $\begin{array}{l}\text { Memilih } \\
\text { menu } \\
\text { tentang }\end{array}$ & $\begin{array}{l}\text { Menampilkan } \\
\text { informasi pembuat } \\
\text { aplikas }\end{array}$ & Berhasil \\
\hline
\end{tabular}

$\begin{array}{lll}\text { Memilih } & \text { Menampilkan video } & \text { Berhasil } \\ \text { menu } & \text { tentang cara } \\ \text { bantuan } & \text { bermain }\end{array}$

\begin{tabular}{clll}
\hline & $\begin{array}{l}\text { Memilih } \\
\text { menu } \\
\text { keluar }\end{array}$ & Keluar dari game & Berhasil \\
\hline 5 & $\begin{array}{l}\text { Mengatur } \\
\text { nama } \\
\text { pemain }\end{array}$ & $\begin{array}{l}\text { Menampilkan form } \\
\text { input nama pemain }\end{array}$ & Berhasil \\
\hline & $\begin{array}{l}\text { Mulai } \\
\text { permainan }\end{array}$ & $\begin{array}{l}\text { Menampilkan } \\
\text { permainan game }\end{array}$ & Berhasil \\
\hline
\end{tabular}

\subsection{Pembahasan}

Hasil pada penelitian ini dilakukan dengan menampilkan sistem yang dibuat. Hasil ini berisi pengujian black box dan pengujian skala likert.

1) Tampilan Utama Game

Pada bagian ini merupakan tampilan awal dari game, dimana terdapat menu play, bantuan, tentang, atur nama pemain, dan keluar pada gambar 6 .

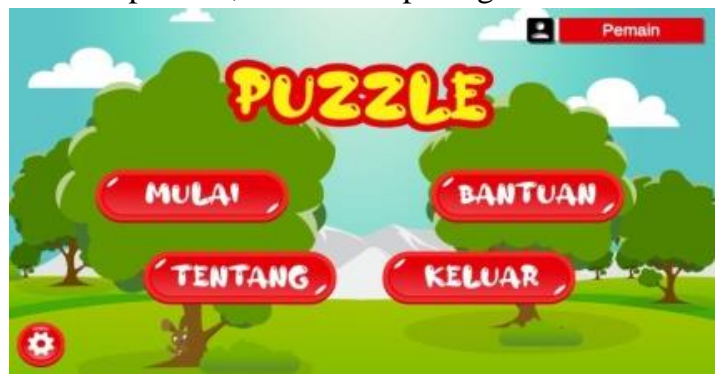

Gambar 6. Halaman utama game

2) Tampilan Menu Play

Pada halaman ini menampilkan merupakan tampilan dimana pemain memilih jenis buah untuk nantinya digunakan sebagai puzzle pada game, seperti pada gambar 7

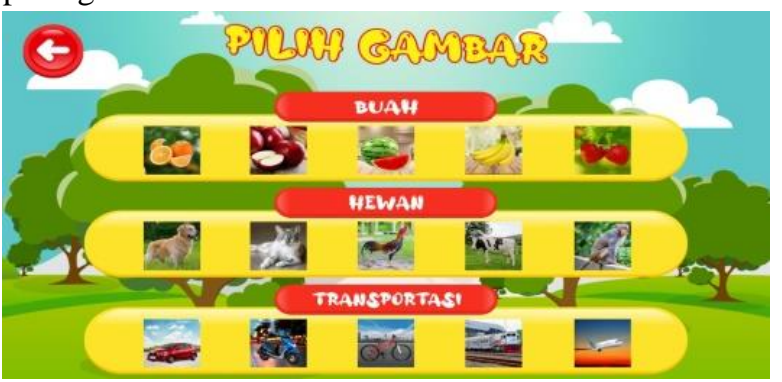

Gambar 7. Tampilan menu play

3) Tampilan Menu Bantuan

Pada halaman ini merupakan tampilan dimana pemain dapat melihat bantuan atau tata cara bermain puzzle pada game seperti pada gambar 8

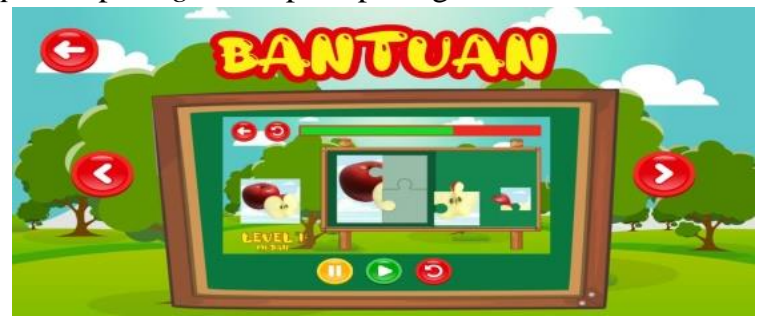

Gambar 8. Halaman menu bantuan

4) Tampilan Menu Tentang

Pada halaman ini merupakan tampilan dimana pemain dapat melihat informasi pembuat game aplikasi puzzle 
Jurnal Ilmiah Ilmu Komputer Vol. 5, No. 1, April 2019

Fakultas Ilmu Komputer

Universitas AL Asyariah Mandar

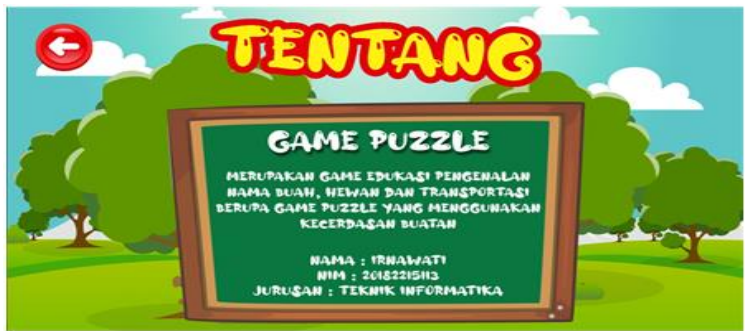

Gambar 9. Halaman menu tentang

5) Tampilan Menu Bahasa

Pada form pilih bahasa, pemain dapat mengatur bahasa pada game puzzle.

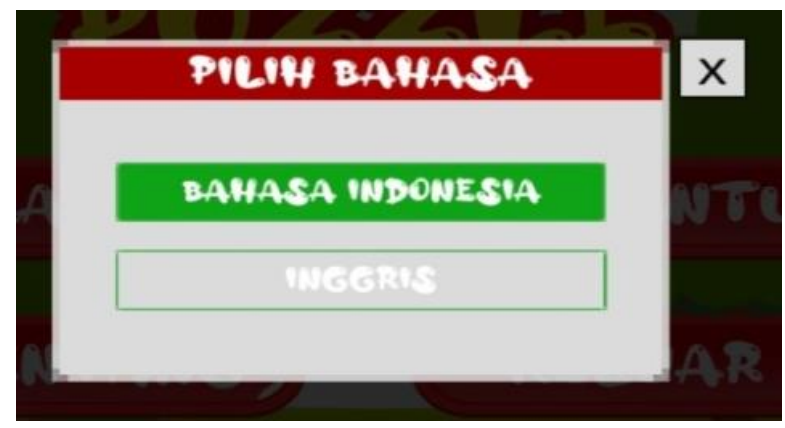

Gambar 10. Halaman menu bahasa

6) Tampilan Menu Nama Pemain

Pada form atur nama pemain, pemain dapat mengatur nama pemain game untuk ditampilkan pada score board.

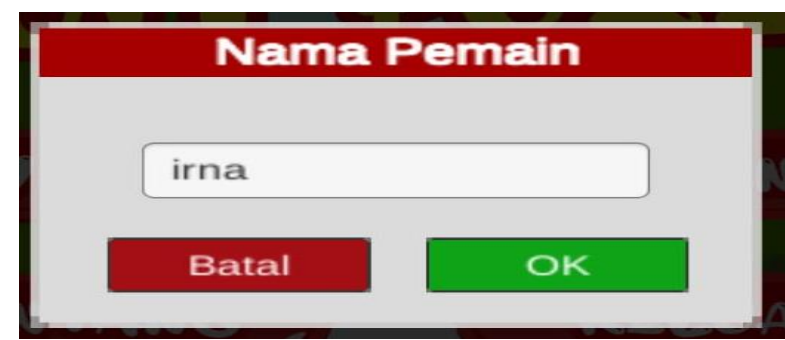

Gambar 11. Form nama pemain

7) Tampilan Menu Level

Pada halaman ini merupakan tampilan dimana pemain memulai permainan game puzzle dari mulai pemilihan level, hingga permainan puzzle selesai.

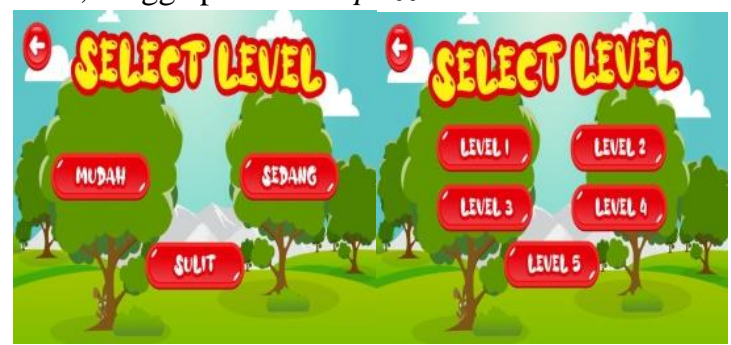

Gambar 12. Tampilan menu level

8) Tampilan Form Permaian

Pada form permainan untuk melakukan penyusunan game puzzle. Pemain harus
(P) ISSN 2442-451X

(O) ISSN 2503-3832

menyelesaikan penyusunan game puzzle sebelum waktu habis.

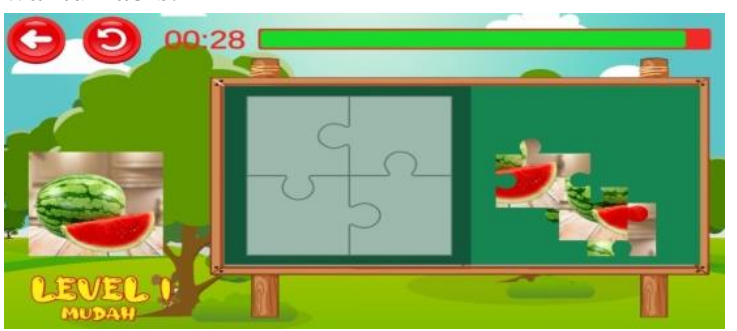

Gambar 13. form permainan

9) Tampilan penyusunan puzzle berhasil

Pemain telah menyelesaikan permainan game puzzle di 1 level. Pemain dapat melanjutkan permainan ke level selanjutnya, melihat score, mengulangi permainan, atau kembali ke halaman pilih level.

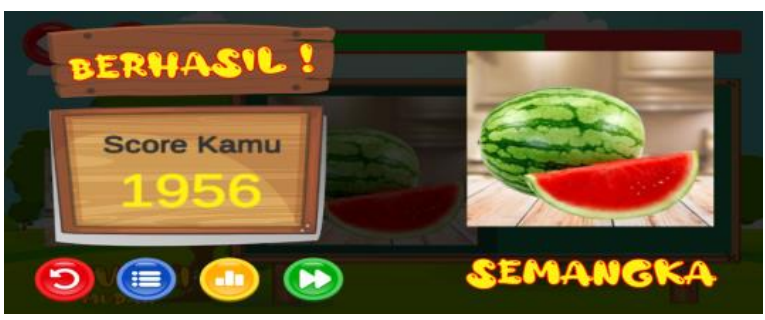

Gambar 14. Form puzzle berhasil

10) Tampilan Form Permaian

Pada saat pemain telah gagal menyelesaikan penyusunan puzzle karena kehabisan waktu, maka pemain dapat melakukan penyusunan ulang atau kembali ke halaman pilih level.

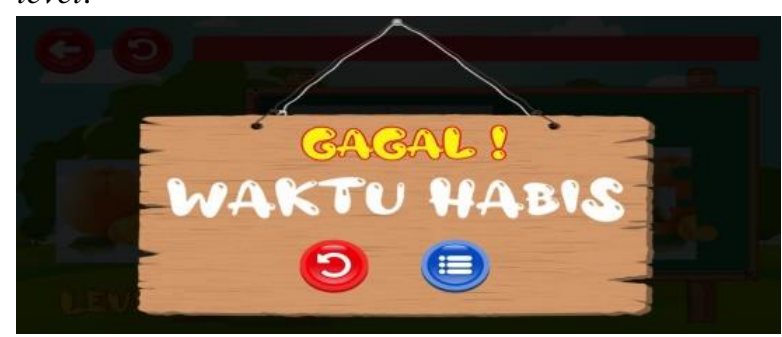

Gambar 15. Form puzzle gagal

11) Tampilan Form Permaian

Pada saat pemain telah gagal menyelesaikan penyusunan puzzle karena kehabisan waktu, maka pemain dapat melakukan penyusunan ulang atau kembali ke halaman pilih level.

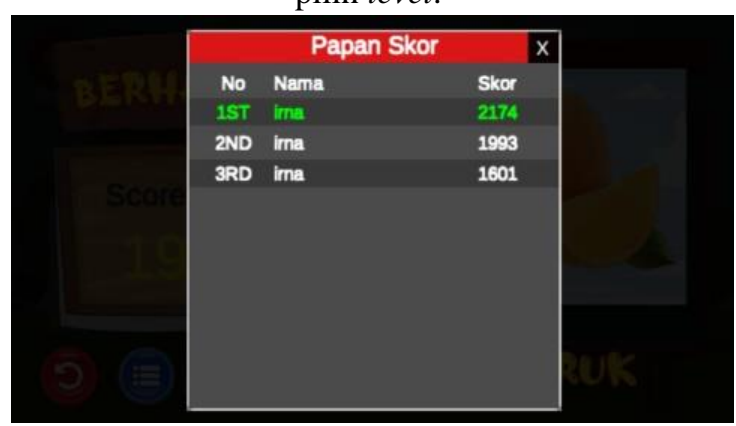


Universitas AL Asyariah Mandar

Gambar 16. Score board pemain

\section{KESIMPULAN}

Bagian ini adalah penutup artikel. Kesimpulan ditulis tanpa angka, dan disajikan dalam bentuk paragraf. Implikasi dan keterbatasan penelitian juga disajikan dalam bentuk paragraf metode.

\subsection{Kesimpulan}

Setelah Setelah semua proses pembuatan aplikasi game edukasi puzzle dengan kecerdasan buatan berbasis android menggunakan sistem kontrol finite state machine (FSM) selesai, maka dapat diambil beberapa kesimpulan sebagai berikut :

1) Game edukasi puzzle ini dibuat menggunakan aplikasi unity 3D dan dengan bahasa pemprograman C\# serta menggunakan sistem kontrol finite state machine dalam pengontrolannya dan algoritma shuffle random dalam pengacangan posisi potongan puzzle dapat dimaikan di platform android.

2) Hasil impementasi menggunakan metode finite state machine yaitu untuk mengacak posisi gambar pada game puzzle. Dimana kondisi yang dipilih sesuai dengan level yang sudah ditentukan akan mengakibatkan perpindahan state dalam FSM, perilaku shuffle random dalam game dirancang agar mengacak objek sebelum ditampilkan. Hasil pengujian angket dari 5 kriteria dengan 12 responden yaitu 96\%, maka dapat disimpulkan bahwa sangat layak.

\subsection{Saran}

Dalam pembuatan aplikasi game edukasi puzzle masih banyak kekurangan, oleh karena itu berdasarkan dari hasil pengujian, maka berikut ini beberapa saran untuk mengembangkan game selanjutnya.

1) Game ini masih dijalankan pada perangkat smartphone android, sehingga perlu dikembangkan lagi agar dapat dijalankan pada perangkat IOS.

2) Memabahkan beberapa notifiaksi pada agent game agar dapat berinteksi lebih banyak dengan user.

\section{Daftar Pustaka}

[1] Agustin, A., Evel, A., Susanti, S., \& Rahmaddeni, R. (2021). Implementasi Metode Finite State Machine pada Permainan Tradisional Setatak Berbasis Android. JATISI (Jurnal Teknik Informatika dan Sistem Informasi), 8(2), 738-751. https://jurnal.mdp.ac.id/index.php/jatisi/article/view/580

Halimsah and Margiso, "Problem Solving Permainan [2] Puzzle 8 Menggunakan Algoritma A*. Pontianak : STMIK Pontianak," STMIK Pontianak, 2014.

[3] F. Nurkholis, "Pengembangan Game Edukasi Pengenalan Nama Hewan dalam Bahasa Inggris untuk Anak SD Berbasis Adobe Flash CS6," Ponogoro : Universitas Muhammadiyah Ponogoro, 2015.

[4] Andarista, P. (2018). Implementasi Non Player Character Pada Game "The Lost Baby" Menggunakan Metode Finite State Machine (Doctoral dissertation, Institut Teknologi Nasional Malang). http://eprints.itn.ac.id/2539/

5] Sugihartono, Psikologi Pendidikan, Yogyakarta: UNY 5] Press, 2007.

[6] F. Hidayat, "Perancangan game Edukasi Puzzle sebagai Media Pembelajaran untuk Anak Usia Dini," 2013.

[7] Hakim, AR, Andrea, Reza, Antoni, Devia, 2016, Membangun Edugame " Baby Zoo Puzle" Berbasis Anroid Dengan Game Agent Implementasi Finite State Machine, Sebatik, STIMIK WICIDA, https://media.neliti.com/media/publications/237603membangun-edugame-baby-zoo-puzzle-berbas78b9b67a.pdf

[8] Putro, B. A., Irawan, J. D., \& Wibowo, S. A. (2021). Kombinasi metode finite state machine dan fuzzy pada game escape from punk hazard. Jati (Jurnal Mahasiswa Teknik Informatika), 5(1), 71-78, https://ejournal.itn.ac.id/index.php/jati/article/view/3276

[9] Anshori. [Online]. Available: https://www.ansoriweb.com/2020/03/pengetianuml.html?m=1. [Accessed 23 Juni 2020].

[10] Dina, "Contoh statechart diagram," 2020. [Online]. Available: https://ngampus.id/contoh-ststechart-diagram. [Accessed 23 Juni 2020]. 
Jurnal Ilmiah Ilmu Komputer Vol. 5, No. 1, April 2019

(P) ISSN 2442-451X

Fakultas Ilmu Komputer

(O) ISSN 2503-3832

Universitas AL Asyariah Mandar 